\title{
Association between Smoking Behavior Patterns and Glycated Hemoglobin Levels in a General Population
}

\author{
Dong-Woo Choi ${ }^{1,2}$, Jooeun Jeon ${ }^{1}$, Sang Ah Lee ${ }^{1,2}$, Kyu-Tae Han ${ }^{3}{ }^{\circledR}$, Eun-Cheol Park ${ }^{2,4}(\mathbb{D}$ and \\ Sung-In Jang ${ }^{2,4, *}$ \\ 1 Department of Public Health, Graduate School, Yonsei University, Seoul 03722, Korea; \\ cdw6027@yuhs.ac (D.-W.C.); jjooeun@yuhs.ac (J.J.); ivory0817@yuhs.ac (S.A.L.) \\ 2 Institute of Health Services Research, Yonsei University, Seoul 03722, Korea; ecpark@yuhs.ac \\ 3 Department of Preventive Medicine, Yonsei University College of Medicine, Seoul 03722, Korea; \\ kthan.phd@gmail.com \\ 4 Department of Policy Research Affairs, National Health Insurance Service Ilsan Hospital, \\ Koyang 10444, Korea \\ * Correspondence: jangsi@yuhs.ac; Tel.: +82-2-2228-1863
}

Received: 8 August 2018; Accepted: 11 October 2018; Published: 16 October 2018

\begin{abstract}
This study investigated the association of smoking behaviors, including dual smoking (smoking both cigarettes and e-cigarettes), cigarettes smoking, and previous smoking, with glycated hemoglobin (HbA1c) levels. National Health and Nutrition Examination Survey (KNHANES) data from 2014-2016 was used. Associations between smoking behavior patterns and HbA1c levels were analyzed via multiple regression. Among 8809 participants, individuals who were dual smokers and cigarettes smokers had significantly higher $\mathrm{HbA1}$ c levels than non-smokers (dual: $\beta=0.1116$, $p=0.0012$, single: $\beta=0.0752, p=0.0022$ ). This relationship strengthened in subgroups of men (dual: $\beta=0.1290, p=0.0013$, single: $\beta=0.1020, p=0.0014$, ex: $\beta=0.0654, p=0.0308$ ), physically inactive subjects (dual: $\beta=0.1527, p=0.0053$, single: $\beta=0.0876, p=0.0197$ ), and overweight (dual: $\beta=0.1425$, $p=0.0133$ ) and obese individuals (dual: $\beta=0.1694, p=0.0061$, single: $\beta=0.1035, p=0.0217$ ). This study suggests that smoking behaviors are likely to increase the risk of HbA1c level in a general population. The health effects of dual smoking remain uncertain and should be addressed in the future.
\end{abstract}

Keywords: HbA1c; dual smoking; type 2 diabetes mellitus; KNHANES

\section{Introduction}

Glycated hemoglobin $(\mathrm{HbA} 1 \mathrm{c})$ is used as one of the standard measures to diagnose diabetes worldwide. $\mathrm{HbA1c}$ has several advantages as a diagnostic method compared with a fasting glucose test, and has been recommended for the determination of glucose control among people who have already diagnosed with diabetes [1-3]. The HbA1c level represents the two to three month average blood glucose level and is therefore used to monitor glycemic control in patients with diabetes $[4,5]$.

Cigarette smoking has been identified as a risk factor for mortality and as the second leading risk factor for early death and disability worldwide [6]. Additionally, individuals with diabetes who smoke are more likely to experience difficulty with insulin dosing and disease control than non-smokers [6]. Notably, previous studies revealed that when compared to non-smokers, cigarette smokers had elevated levels of $\mathrm{HbA1c}$, as well as a 30-40\% higher risk of type 2 diabetes [7-9]. Moreover, the prevalence of e-cigarette use in South Korea was 7.1\% for men and 1.2\% for women in 2015 , which had increased by $2.7 \%$ in men and $0.8 \%$ in women compared to 2014 [10]. Electronic cigarettes (e-cigarettes), which aerosolize nicotine to produce a vapor that purportedly contains fewer 
traditional toxins than secondhand smoke, are used to emulate cigarette smoking. These devices are popular for smoking cessation and reduction among those who wish to eliminate or reduce cigarette use [11-13], and several studies have reported the positive effects of e-cigarettes for this purpose $[14,15]$. However, the effects of e-cigarettes use have not been as fully elucidated as those of cigarettes, and it remains uncertain whether these devices are safe for use by individuals interested in smoking cessation and reduction. Moreover, dual smoking, which includes using both e-cigarettes and ordinary cigarettes, has been revealed to likely induce tobacco dependence, although its other health effects are still unknown [16].

Unlike evidence related to cigarette smoking, there is insufficient evidence to clarify the relationship between dual smoking or e-cigarettes smoking and $\mathrm{HbA1c}$ levels. Therefore, this study investigated the association of various smoking behaviors, including dual smoking, cigarettes alone, and previous smoking, with $\mathrm{HbA1c}$ levels in a general population.

\section{Methods}

\subsection{Study Population}

This cross-sectional study was based on data from the 2014-2016 Korea National Health and Nutrition Examination Survey (KNHANES), a nationwide survey conducted by the Korea Centers for Disease Control (KCDC) and Prevention. From a database of 23,080 participants, we excluded patients who had received a diagnosis of diabetes from a physician, had used medication for diabetes, and had $\mathrm{HbA} 1 \mathrm{c}$ levels $<6.5 \%$ (48 $\mathrm{mmol} / \mathrm{mol})$. We also excluded participants for whom information was unavailable regarding smoking behavior, $\mathrm{HbA1c}$ level, age, sex, occupation, household income, educational level, physical activity, body mass index (BMI), alcoholic behavior, pack-years of smoking, anemia status, family history of diabetes mellitus, and caloric intake. Finally, a total of 8,809 participants were included in this study.

\subsection{Variables}

The percent $\mathrm{HbA} 1 \mathrm{c}$ was set as the dependent variable and was determined using high performance liquid chromatography. Smoking behavior, which combined cigarette and e-cigarette use, was the primary independent variable. The survey asked all subjects whether they used cigarettes or e-cigarettes currently or had ever used these products during their lifetime. Accordingly, we classified the subjects into four categories: dual smokers (both cigarettes and e-cigarette), single smokers (cigarettes smokers), former smokers (ex-smokers), and non-smokers.

The covariates included age, sex, occupation, household income, educational level, BMI, physical activity, pack-years of cigarette smoking, alcoholic behavior, family history of diabetes mellitus, year, and caloric intake. Age was stratified into 10-year periods of 20-29, 30-39, 40-49, 50-59, 60-69, and $\geq 70$ years. Socioeconomic status was stratified into four groups by household income level from 1 quartile (low) to 4 quartiles (high). Obesity was defined as a BMI $\geq 25$. Physical activity, which was self-reported, was stratified by the World Health Organization recommendations (WHO) that adults should perform at least $150 \mathrm{~min}$ of moderate-intensity or $75 \mathrm{~min}$ of vigorous-intensity aerobic physical activity, or an equivalent combination of both types, throughout the week. Pack year of cigarette smoking for the lifetime was calculated by multiplying the daily smoking amount by the smoking period by referring to the previous study. Pack-year of cigarette smoking for the lifetime was calculated by multiplying the daily smoking amount by the smoking period by referring to the previous study which classified this data as none, light ( $\leq 26.7$ pack-years), medium (26.8-40.4 pack-years), heavy (40.5-55.5 pack-years), and very heavy ( $>55.5$ pack-years) $[17,18]$. Alcoholic behavior was defined as the intake of such beverages above 1 times/day, $1-4$ times per month, and $\geq 2$ times/week. A family history of diabetes was defined as having an immediate family member (e.g., father, mother, brother, and/or sister) with type 1 or type 2 diabetes. The caloric intake was determined as the number of kcals consumed per day, which was calculated by multiplying $4 \mathrm{kcal} / \mathrm{g}$ by intake of carbohydrates and 
protein and $9 \mathrm{kcal} / \mathrm{g}$ by intake of fat, divided by the total energy consumed during the day, and then multiplied by 100 .

\subsection{Statistical Analysis}

For all analyses, we used the sampling weights variable provided by KNHANES. First, we examined the distribution of the study population in terms of the frequency and percentage of each categorized variable, and then determined the mean and standard deviation for the distribution of each continuous variable. The Kolmogorov-Smirnov goodness-of-fit test was used to test the normality of distribution for HbA1c. As this variable was not normally distributed, we excluded outliers to improve normality. Next, we used an analysis of variance (ANOVA) to compare the average $\mathrm{HbA1c}$ levels according to independent variables. A multiple regression analysis including weight as a variable was used to estimate the association between smoking behavior patterns and $\mathrm{HbA} 1 \mathrm{c}$ after controlling for age, sex, occupation, household income, educational level, physical activity, BMI, alcoholic behavior, pack-years of smoking, family history of diabetes mellitus, year, and caloric intake. Finally, we performed the multiple regression analysis of subgroups stratified by sex and physical activity, and BMI. All statistical analyses were performed using SAS version 9.4 (SAS Institute, Inc., Cary, NC, USA). A $p$-value $<0.05$ was considered statistically significant.

\subsection{Ethical Statement}

The Korea National Health and Nutrition Examination Survey data are openly published, thus, ethical approval was not required for this study. This study did not require informed consent from the participants, as their information was fully anonymized and unidentified prior to analysis.

\section{Results}

Table 1 presents the distribution of the study population. Regarding smoking behaviors, dual smokers, single smokers, ex-smokers, and non-smokers accounted for $1.61 \%(n=142)$, $15.43 \%(n=1359), 18.78 \%(n=1654)$, and $64.18 \%(n=5654)$ of the sample, respectively. Men and women comprised $39.99 \%(n=3523)$ and $60.01 \%(n=5286)$ of the sample, respectively. Normal weight/underweight, overweight, and obese subjects comprised $46.48 \%(n=4094), 22.90 \%(n=2017)$, and $30.63 \%(n=2698)$ of the sample, respectively. The overall mean HbA1c level was $5.48 \pm 0.27 \%$.

Table 1. The general characteristics of study population.

\begin{tabular}{lccccc}
\hline Variables & & & \multicolumn{3}{c}{ HbA1c } \\
& N/Mean & \%/SD & Mean & SD & $p$-Value \\
\hline Smoking Behavior & & & & & $<0.0001$ \\
$\quad$ Dual smokers & 142 & 1.61 & 5.48 & \pm 0.34 & \\
$\quad$ Single smokers & 1359 & 15.43 & 5.50 & \pm 0.27 & \\
$\quad$ Ex-smoker & 1654 & 18.78 & 5.51 & \pm 0.27 & \\
$\quad$ Non-smoker & 5654 & 64.18 & 5.47 & \pm 0.27 & \\
Sex & & & & & 0.7098 \\
$\quad$ Men & 3523 & 39.99 & 5.50 & \pm 0.27 & \\
$\quad$ Women & 5286 & 60.01 & 5.48 & \pm 0.27 & \\
Age (years) & & & & & $<0.0001$ \\
$\quad$ 20-30 & 1176 & 13.35 & 5.26 & \pm 0.21 & \\
$\quad 30-39$ & 1930 & 21.91 & 5.37 & \pm 0.23 & \\
$\quad 40-49$ & 1772 & 20.12 & 5.44 & \pm 0.23 & \\
50-59 & 1692 & 19.21 & 5.57 & \pm 0.23 & \\
$\quad 60-69$ & 1314 & 14.92 & 5.65 & \pm 0.24 & \\
$\quad 70$ & 925 & 10.50 & 5.70 & \pm 0.24 & \\
\hline
\end{tabular}


Table 1. Cont.

\begin{tabular}{|c|c|c|c|c|c|}
\hline \multirow{2}{*}{ Variables } & \multirow{2}{*}{ N/Mean } & \multirow{2}{*}{$\% / S D$} & \multicolumn{3}{|c|}{ HbA1c } \\
\hline & & & Mean & SD & $p$-Value \\
\hline Household Income & & & & & 0.057 \\
\hline Low & 2821 & 32.02 & 5.45 & \pm 0.26 & \\
\hline Mid-low & 2641 & 29.98 & 5.46 & \pm 0.26 & \\
\hline Mid-high & 2122 & 24.09 & 5.50 & \pm 0.27 & \\
\hline High & 1225 & 13.91 & 5.59 & \pm 0.28 & \\
\hline Occupational Categories & & & & & 0.0913 \\
\hline White collar worker & 2371 & 26.92 & 5.41 & \pm 0.25 & \\
\hline Pink collar worker & 1154 & 13.10 & 5.47 & \pm 0.26 & \\
\hline Blue collar worker & 1901 & 21.58 & 5.55 & \pm 0.26 & \\
\hline Unemployed & 3383 & 38.40 & 5.50 & \pm 0.28 & \\
\hline Educational Level & & & & & 0.0703 \\
\hline High school & 4455 & 50.57 & 5.56 & \pm 0.26 & \\
\hline University or College & 3831 & 43.49 & 5.40 & \pm 0.25 & \\
\hline Graduated school & 523 & 5.94 & 5.42 & \pm 0.26 & \\
\hline BMI & & & & & $<0.0001$ \\
\hline Normal/underweight $(<23)$ & 4094 & 46.48 & 5.41 & \pm 0.25 & \\
\hline Overweight (23-24.9) & 2017 & 22.90 & 5.50 & \pm 0.25 & \\
\hline Obesity $(\geq 25)$ & 2698 & 30.63 & 5.59 & \pm 0.27 & \\
\hline Physical Activity & & & & & 0.1061 \\
\hline Yes & 4495 & 51.03 & 5.46 & \pm 0.27 & \\
\hline No & 4314 & 48.97 & 5.51 & \pm 0.27 & \\
\hline $\begin{array}{l}\text { Pack Year of Cigarette } \\
\text { Smoking }\end{array}$ & & & & & $<0.0001$ \\
\hline Very heavy & 173 & 1.96 & 5.66 & \pm 0.28 & \\
\hline Heavy & 188 & 2.13 & 5.65 & \pm 0.26 & \\
\hline Medium & 474 & 5.38 & 5.63 & \pm 0.26 & \\
\hline Light & 2248 & 25.52 & 5.46 & \pm 0.26 & \\
\hline None & 5726 & 65.00 & 5.47 & \pm 0.27 & \\
\hline Alcoholic Behavior & & & & & $<0.0001$ \\
\hline less than 1 time for a month & 3974 & 45.11 & 5.53 & \pm 0.27 & \\
\hline $1-4$ times for a month & 3008 & 34.15 & 5.44 & \pm 0.26 & \\
\hline 2 times or above for a week & 1827 & 20.74 & 5.46 & \pm 0.27 & \\
\hline Family History of Diabetes & & & & & $<0.0001$ \\
\hline Present & 1986 & 22.55 & 5.52 & \pm 0.27 & \\
\hline Absent & 6823 & 77.45 & 5.47 & \pm 0.27 & \\
\hline Year & & & & & $<0.0001$ \\
\hline 2014 & 2684 & 30.47 & 5.53 & \pm 0.27 & \\
\hline 2015 & 2870 & 32.58 & 5.47 & \pm 0.27 & \\
\hline 2016 & 3255 & 36.95 & 5.45 & \pm 0.27 & \\
\hline Caloric Intake † & 2054.72 & \pm 940.62 & & & \\
\hline Total & 8809 & 100.00 & 5.48 & \pm 0.27 & \\
\hline
\end{tabular}

† Mean and Standard deviation (SD) of the continuous independent variables in this study.

Table 2 demonstrates the associations of smoking behavior with covariates and $\mathrm{HbA} 1 \mathrm{c}$ levels. Of the smoking behavior groups, dual smokers and single smokers had significantly higher $\mathrm{HbA} 1 \mathrm{c}$ levels than non-smokers (dual: $\beta=0.1116, p=0.0012$, single: $\beta=0.0752, p=0.0022$ ). HbA1c levels tended to increase significantly with age (30-39 years: $\beta=0.0856,40-49: \beta=0.1538,50-59: \beta=0.2648$, 60-69: $\beta=0.3477$, and $\geq 70: \beta=0.4147, p<0.0001$ vs. $20-29$ years), BMI (overweight: $\beta=0.0547$ and obesity: $\beta=0.1457, p<0.0001$ vs. normal/underweight), education level (high school: $\beta=0.0218$, $p=0.0361$, university or college: $\beta=0.0217, p=0.0221$ vs. graduated school), and physical activity (no: $\beta=0.0121, p=0.0079$ vs. yes). However, household income, occupation, pack-years of cigarette smoking, and caloric intake had no significant effect on this association. 
Table 2. The results of multiple regression analysis to investigate the association between smoking behavior patterns and $\mathrm{HbA} 1 \mathrm{c}$.

\begin{tabular}{|c|c|c|c|}
\hline \multirow{2}{*}{ Variables } & \multicolumn{3}{|c|}{ HbA1c } \\
\hline & $\beta$ & SE & $p$-Value \\
\hline \multicolumn{4}{|l|}{ Smoking Behavior } \\
\hline Dual smokers & 0.1116 & 0.0343 & 0.0012 \\
\hline Single smokers & 0.0752 & 0.0245 & 0.0022 \\
\hline Ex-smoker & 0.0261 & 0.0234 & 0.2647 \\
\hline Non-smoker & Ref & - & - \\
\hline \multicolumn{4}{|l|}{ Sex } \\
\hline Men & -0.0184 & 0.0072 & 0.0114 \\
\hline Women & Ref & - & - \\
\hline \multicolumn{4}{|l|}{ Age (years) } \\
\hline $20-30$ & Ref & - & - \\
\hline $30-39$ & 0.0856 & 0.0079 & $<0.0001$ \\
\hline $40-49$ & 0.1538 & 0.0082 & $<0.0001$ \\
\hline $50-59$ & 0.2648 & 0.0091 & $<0.0001$ \\
\hline $60-69$ & 0.3477 & 0.0100 & $<0.0001$ \\
\hline$\geq 70$ & 0.4147 & 0.0122 & $<0.0001$ \\
\hline \multicolumn{4}{|l|}{ Household Income } \\
\hline Low & Ref & - & - \\
\hline Mid-low & 0.0062 & 0.0088 & 0.4848 \\
\hline Mid-high & 0.0090 & 0.0089 & 0.3126 \\
\hline High & 0.0093 & 0.0091 & 0.3096 \\
\hline \multicolumn{4}{|l|}{ Occupational Categories } \\
\hline White collar worker & -0.0019 & 0.0061 & 0.7514 \\
\hline Pink collar worker & 0.0086 & 0.0074 & 0.2426 \\
\hline Blue collar worker & 0.0089 & 0.0069 & 0.1998 \\
\hline Unemployed & Ref & - & - \\
\hline \multicolumn{4}{|l|}{ Educational Level } \\
\hline High school & 0.0218 & 0.0104 & 0.0361 \\
\hline University or College & 0.0217 & 0.0095 & 0.0221 \\
\hline Graduated school & Ref & - & - \\
\hline \multicolumn{4}{|l|}{ BMI } \\
\hline Normal or underweight $(<23)$ & Ref & - & - \\
\hline Overweight (23-24.9) & 0.0547 & 0.0058 & $<0.0001$ \\
\hline Obesity $(\geq 25)$ & 0.1457 & 0.0055 & $<0.0001$ \\
\hline \multicolumn{4}{|l|}{ Physical Activity } \\
\hline Yes & Ref & - & - \\
\hline No & 0.0121 & 0.0045 & 0.0079 \\
\hline \multicolumn{4}{|l|}{ Pack Year of Cigarette Smoking } \\
\hline Very heavy & -0.0061 & 0.0315 & 0.8478 \\
\hline Heavy & 0.0223 & 0.0294 & 0.4471 \\
\hline Medium & 0.0447 & 0.0260 & 0.0861 \\
\hline Light & -0.0163 & 0.0235 & 0.4886 \\
\hline None & Ref & - & - \\
\hline \multicolumn{4}{|l|}{ Alcoholic Behavior } \\
\hline less than 1 time for a month & Ref & - & - \\
\hline 1-4 times for a month & -0.0282 & 0.0056 & $<0.0001$ \\
\hline 2 times or above for a week & -0.0628 & 0.0069 & $<0.0001$ \\
\hline \multicolumn{4}{|l|}{ Family History of Diabetes } \\
\hline Present & 0.0530 & 0.0056 & $<0.0001$ \\
\hline Absent & Ref & - & - \\
\hline \multicolumn{4}{|l|}{ Year } \\
\hline 2014 & 0.0822 & 0.0062 & $<0.0001$ \\
\hline 2015 & 0.0078 & 0.0063 & 0.2141 \\
\hline 2016 & Ref & - & - \\
\hline Caloric intake & 0.0000 & 0.0000 & 0.4240 \\
\hline
\end{tabular}


Figure 1 presents the results of subgroup analyses according to sex, physical activity, and BMI. Men who were dual, single, and ex-smokers had significantly higher HbA1c levels, compared to non-smokers (dual: $\beta=0.1290, p=0.0013$, single: $\beta=0.1020, p=0.0014$, ex-smoker: $\beta=0.654$, $p=0.0308$ ). Among females, there was no difference in $\mathrm{HbA} 1 \mathrm{c}$ levels across the exposure categories. Physically inactive subjects who were dual and single smokers had significantly higher $\mathrm{HbA1c}$ levels than non-smokers (dual: $\beta=0.1527, p=0.0053$, single: $\beta=0.0876, p=0.0197$ ). Subjects who were single smokers and performed physical activity according to WHO recommendations also had significantly higher $\mathrm{HbA1c}$ levels than non-smokers $(\beta=0.0672, p=0.0344)$. Among obese participants, dual and single smokers had significantly higher HbA1c levels, compared to non-smokers (dual: $\beta=0.1694$, $p=0.0061$, single: $\beta=0.1035, p=0.0217$ ). Subjects who were dual smokers and overweight exhibited higher HbA1c levels than non-smokers $(\beta=0.1425, p=0.0133)$. However, there were no significant results in normal/underweight subjects. 


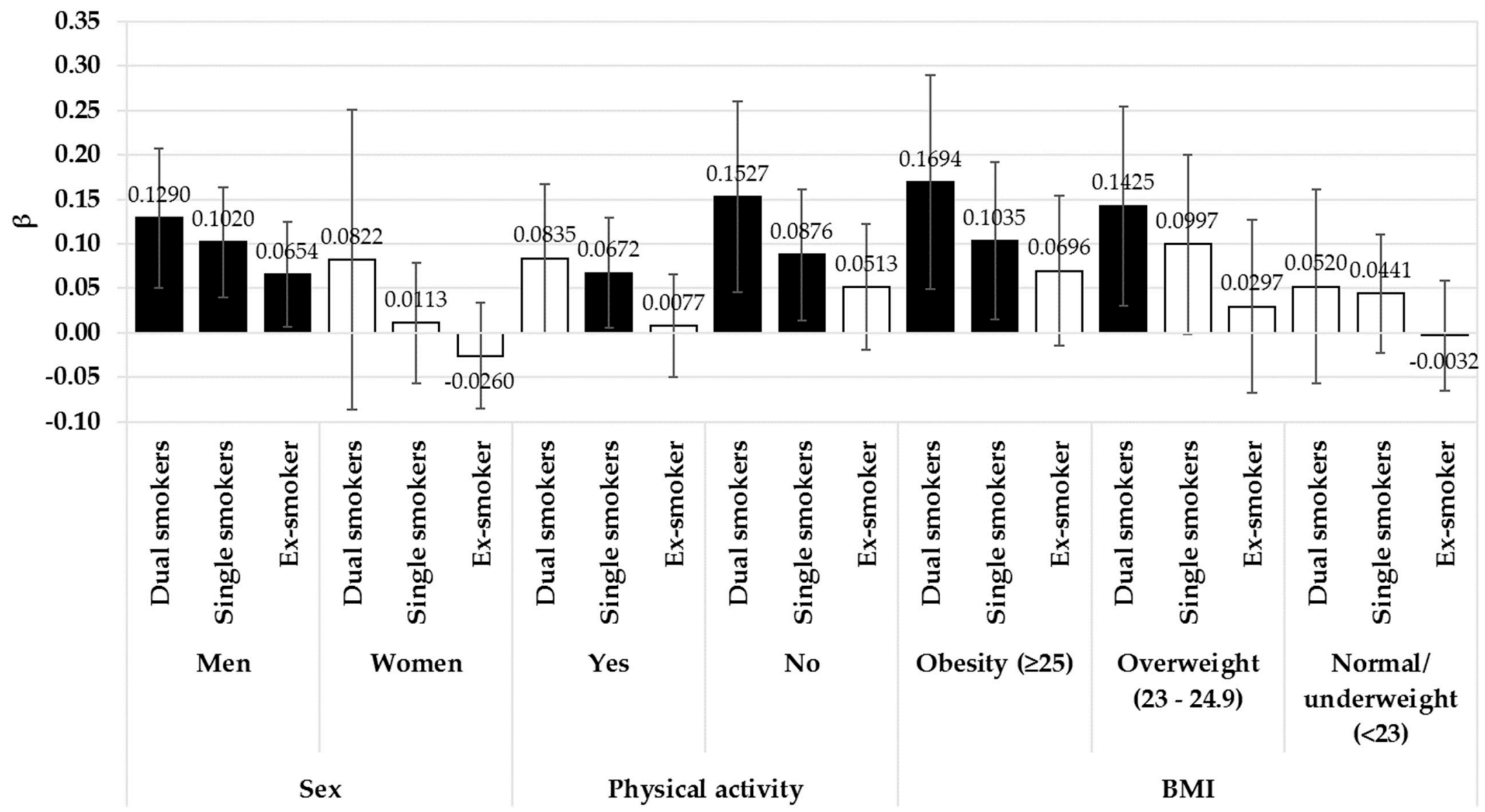

Figure 1. The results of subgroup analysis with multiple regression to investigate the association between smoking behavior and HbA1c according to sex, physical activity, and BMI. Black bars are statistically significant results $(p<0.05)$. Non-smokers were the reference group. Analyses were adjusted for the following covariates: age, sex, occupation, household income, educational level, BMI, physical activity, pack-years of cigarette smoking, alcoholic behavior, family history of diabetes mellitus, year, and caloric intake. 


\section{Discussion}

In this study of a general population, we observed elevated $\mathrm{HbA1c}$ levels among subjects who were both dual and single smokers compared to among non-smokers. These relationships were particularly strong among male, physically inactive, and obese subjects.

Cigarette smoking has been revealed to increase $\mathrm{HbA1c}$ levels in patients without diabetes. One of the previous studies revealed that cigarette smoking was associated with an increase in $\mathrm{HbA1c}$ in the general population $[19,20]$. In addition, one study found that e-cigarettes smokers are likely to have a high $\mathrm{HbA1c}$ level compared to cigarette smokers [21]. A possible explanation for this could be the increase in the rate of glycation of $\mathrm{HbA1c}$ induced by exposure to glycotoxin from cigarette smoke or the relatively high degree of tissue hypoxia [22]. Therefore, these results support our findings regarding the effects of dual cigarette smoking in our sample. However, we were unable to determine direct associations between e-cigarette smoking and $\mathrm{HbA1c}$ levels.

In the analyses stratified by sex, men who were dual and single smokers had higher $\mathrm{HbA} 1 \mathrm{c}$ levels than non-smokers, whereas among women, there were no significant results. Although no clear evidence supports a link between dual smoking and increased $\mathrm{HbA1c}$ levels, several studies have supported the association between cigarette smoking and $\mathrm{HbA1c}$ levels. One of the previous studies revealed that cigarette smoking was independently associated with higher $\mathrm{HbA1c}$ concentrations in both men and women [8]. Evidence suggests a dose-response relationship with the number of cigarettes smoked among current smokers, and an inverse association of the number of years since smoking cessation with $\mathrm{HbA1c}$ levels has been observed among male ex-smokers.

In our analysis, we also stratified smoking behaviors by physical activity levels. Among physically inactive subjects, dual smokers who participated in both cigarette smoking and e-cigarette smoking were more strongly associated with HbA1c levels. Potentially, lifestyle factors such as physical inactivity and dual smoking act synergistically to elevate $\mathrm{HbA1c}$ levels. The ability of physical activity to reduce $\mathrm{HbA1c}$ levels is well-known, and regular physical activity is recommended by healthcare providers or professionals as a beneficial practice [23-25]. These results may corroborate our findings of higher $\mathrm{HbA} 1 \mathrm{c}$ levels among dual smokers who were smoking both e-cigarettes and cigarettes than among non-smokers among physically active subjects. However, it remains unclear whether e-cigarette smoking alone can induce an increase in more $\mathrm{HbA1c}$ levels. Future studies should investigate the effects of e-cigarette use on $\mathrm{HbA1c}$ levels.

According to BMI, dual smokers had a strong association of elevated $\mathrm{HbA1c}$ levels among people who were obese and overweight compared to those who were normal and underweight. These results may be due to the fact that smoking is likely to increase obesity-related comorbidities associated with visceral adiposity. Therefore, smokers tended to be obese compared to non-smokers [26]. Moreover, a previous study revealed that visceral adiposity was associated with $\mathrm{HbA1c}$ [27]. We guess that these potential biological mechanisms are underlying the strong association between dual smoking and elevated $\mathrm{HbA} 1 \mathrm{c}$ levels compared to non-smoking among obese people compared to normal and underweight people.

This study had several limitations of note. First, as this was a cross-sectional study, the causal relationship between smoking behavior patterns and $\mathrm{HbA} 1 \mathrm{c}$ levels should be interpreted cautiously. Second, we were not able to consider the type of e-cigarette, frequency of vaping, or concentration of nicotine. Third, data regarding smoking behavior, health behavior, and socioeconomic status were collected via self-report surveys and thus might have been subject to recall bias and underestimated smoking behaviors. Fourth, caloric intake was measured indirectly. Fifth, we could not find references about association between dual smoking and $\mathrm{HbA} 1 \mathrm{c}$ although we tried to find previous studies. Therefore, we could not provide enough discussion about dual smoking. Sixth, we could not consider each single e-cigarette smoking behavior because the number of single e-cigarette smokers was very small. Therefore, further study should consider each single smoking behavior. Finally, we may not have fully accounted for confounding factors in our analysis. 
Despite these limitations, however, our study had several strengths. First, our analysis used $\mathrm{HbA1c}$ levels which reflect average plasma glucose over the previous eight to twelve weeks and are able to be measured at any time of day, regardless of the duration of fasting. Second, $\mathrm{HbA1c}$ levels were measured using clinical tests, therefore producing reliable and clear data. Third, few other studies have evaluated the association between smoking behavior, including e-cigarettes, and $\mathrm{HbA} 1 \mathrm{c}$ levels. Thus, this study might provide the impetus to seek the association between smoking behavior, especially dual smoking, and $\mathrm{HbA1c}$. Finally, our study adjusted several social factors known as potential confounders for smoking behaviors or $\mathrm{HbA1c}$, including sex, socioeconomic status, and health behaviors, to appropriately estimate associations among smoking behavior patterns.

\section{Conclusions}

Smoking behaviors, especially dual smokers who use e-cigarettes and cigarettes, were found to likely result in increased $\mathrm{HbA1c}$ levels in a general population, particularly among male, physically inactive, and obese adults. This study is one of the first to attempt to examine the combined and individual effects of cigarettes and e-cigarettes on $\mathrm{HbA} 1 \mathrm{c}$ levels.

We note that unlike cigarettes, the health effects of dual smoking have not been fully elucidated. Although we found that dual smoking both cigarettes and e-cigarettes is unhealthy, it remains unclear whether e-cigarette use affects other health outcomes. Therefore, more studies should explore the adverse health effects of e-cigarettes specifically and/or that we should educate physicians and their patients about the risks of e-cigarettes. This may be especially important since many people believe that e-cigarettes are "safe".

Author Contributions: D.-W.C. participated in designing the study, interpretation of the data, and writing the initial manuscript. J.J. and S.A.L. participated in analyzing the data. K.-T.H. and E.-C.P. reviewed the manuscript. S.-I.J. is the guarantor of this work and, as such, had full access to all the data in the study and takes responsibility for the integrity of the data and the accuracy of the data analysis.

Funding: This research received no external funding.

Conflicts of Interest: The authors declare no competing interests.

\section{References}

1. Nathan, D.M. International expert committee report on the role of the A1C assay in the diagnosis of diabetes. Diabetes Care 2009, 32, 1327-1334. [CrossRef]

2. Selvin, E.; Crainiceanu, C.M.; Brancati, F.L.; Coresh, J. Short-term variability in measures of glycemia and implications for the classification of diabetes. Arch. Internal Med. 2007, 167, 1545-1551. [CrossRef] [PubMed]

3. Rohlfing, C.; Wiedmeyer, H.M.; Little, R.; Grotz, V.L.; Tennill, A.; England, J.; Madsen, R.; Goldstein, D. Biological variation of glycohemoglobin. Clin. Chem. 2002, 48, 1116. [PubMed]

4. Rohlfing, C.L.; Wiedmeyer, H.M.; Little, R.R.; England, J.D.; Tennill, A.; Goldstein, D.E. Defining the relationship between plasma glucose and $\mathrm{HbA1c}$ : Analysis of glucose profiles and $\mathrm{HbA1} \mathrm{c}$ in the diabetes control and complications trial. Diabetes Care 2002, 25, 275. [CrossRef] [PubMed]

5. Barr, R.; Nathan, D.M.; Meigs, J.B.; Singer, D.E. Tests of glycemia for the diagnosis of type 2 diabetes mellitus. Ann. Internal Med. 2002, 137, 263-272. [CrossRef]

6. In The Health Consequences of Smoking-50 Years of Progress: A Report of the Surgeon General. 2014. Available online: https://www.surgeongeneral.gov/library/reports/50-years-of-progress/index.html (accessed on 29 January 2018).

7. Chang, S.A. Smoking and type 2 diabetes mellitus. Diabetes Metab. J. 2012, 36, 399-403. [CrossRef] [PubMed]

8. Sargeant, L.A.; Khaw, K.T.; Bingham, S.; Day, N.E.; Luben, R.N.; Oakes, S.; Welch, A.; Wareham, N.J. Cigarette smoking and glycaemia: The EPIC-Norfolk Study. Int. J. Epidemiol. 2001, 30, 547-554. [CrossRef] [PubMed]

9. Hong, J.W.; Ku, C.R.; Noh, J.H.; Ko, K.S.; Rhee, B.D.; Kim, D.J. Association between self-reported smoking and hemoglobin A1c in a Korean population without diabetes: The 2011-2012 Korean National Health and Nutrition Examination Survey. PLoS ONE 2015, 10, e0126746. [CrossRef] [PubMed] 
10. Korea Health Statistics 2015: 6th Korea National Health and Nutrition Examination Survey. Available online: https:/ / knhanes.cdc.go.kr/knhanes/sub04/sub04_03.do (accessed on 21 December 2016).

11. Caponnetto, P.; Campagna, D.; Cibella, F.; Morjaria, J.B.; Caruso, M.; Russo, C.; Polosa, R. Efficiency and safety of an electronic cigarette (ECLAT) as tobacco cigarettes substitute: A prospective 12-month randomized control design study. PLoS ONE 2013, 8, e66317. [CrossRef] [PubMed]

12. Etter, J.F.; Bullen, C. Electronic cigarette: Users profile, utilization, satisfaction and perceived efficacy. Addiction 2011, 106, 2017-2028. [CrossRef] [PubMed]

13. Goniewicz, M.L.; Lingas, E.O.; Hajek, P. Patterns of electronic cigarette use and user beliefs about their safety and benefits: An internet survey. Drug Alcohol Rev. 2013, 32, 133-140. [CrossRef] [PubMed]

14. Bullen, C.; Howe, C.; Laugesen, M.; McRobbie, H.; Parag, V.; Williman, J.; Walker, N. Electronic cigarettes for smoking cessation: A randomised controlled trial. Lancet 2013, 382, 1629-1637. [CrossRef]

15. Vickerman, K.A.; Carpenter, K.M.; Altman, T.; Nash, C.M.; Zbikowski, S.M. Use of electronic cigarettes among state tobacco cessation quitline callers. Nicotine Tob. Res. 2013, 15, 1787-1791. [CrossRef] [PubMed]

16. Tomar, S.L.; Alpert, H.R.; Connolly, G.N. Patterns of dual use of cigarettes and smokeless tobacco among US males: Findings from national surveys. Tob. Control 2010, 19, 104. [CrossRef] [PubMed]

17. Juan, D.; Zhou, D.H.D.; Li, J.; Wang, J.Y.J.; Gao, C.; Chen, M. A 2-year follow-up study of cigarette smoking and risk of dementia. Eur. J. Neurol. 2004, 11, 277-282. [CrossRef] [PubMed]

18. Tyas, S.L.; White, L.R.; Petrovitch, H.; Webster-Ross, G.; Foley, D.J.; Heimovitz, H.K.; Launer, L.J. Mid-life smoking and late-life dementia: The Honolulu-Asia aging study. Neurobiol. Aging 2003, 24, 589-596. [CrossRef]

19. Clair, C.; Bitton, A.; Meigs, J.B.; Rigotti, N.A. Relationships of cotinine and self-reported cigarette smoking with hemoglobin A1c in the U.S. Diabetes Care 2011, 34, 2250-2255. [CrossRef] [PubMed]

20. Nishida, Y.; Hara, M.; Nanri, H.; Nakamura, K.; Imaizumi, T.; Sakamoto, T.; Higaki, Y.; Taguchi, N.; Horita, M.; Shinchi, K.; et al. Interaction between interleukin1- $\beta$ gene polymorphism and cigarette smoking on $\mathrm{HbA1c}$ in a Japanese general population. Int. J. Epidemiol. 2015, 44, i193-i194. [CrossRef]

21. Hoskinson, H. Effects of Chronic Electronic Cigarette Use on Glucose Metabolism. West Virginia University. 2017. Available online: https:/ / search.proquest.com/docview/1958944760?accountid=15179 (accessed on 29 January 2018).

22. Jansen, H.; Stolk, R.P.; Nolte, I.M.; Kema, I.P.; Wolffenbuttel, B.H.R.; Snieder, H. Determinants of HbA1c in nondiabetic Dutch adults: Genetic loci and clinical and lifestyle parameters, and their interactions in the lifelines cohort study. J. Int. Med. 2012, 273, 283-293. [CrossRef] [PubMed]

23. Umpierre, D.; Ribeiro, P.A.B.; Kramer, C.K.; Leitao, C.B.; Zucatti, A.T.N.; Azevedo, M.J.; Gross, J.L.; Ribeiro, J.P.; Schaan, B.D. Physical activity advice only or structured exercise training and association with hba1c levels in type 2 diabetes: A systematic review and meta-analysis. JAMA 2011, 305, 1790-1799. [CrossRef] [PubMed]

24. Mikus, C.R.; Oberlin, D.J.; Libla, J.L.; Taylor, A.M.; Booth, F.W.; Thyfault, J.P. Lowering physical activity impairs glycemic control in healthy volunteers. Med. Sci. Sports Exerc. 2012, 44, 225-231. [CrossRef] [PubMed]

25. Chomistek, A.K.; Chiuve, S.E.; Jensen, M.K.; Cook, N.R.; Rimm, E.B. Vigorous physical activity, mediating biomarkers, and risk of myocardial infarction. Med. Sci. Sports Exerc. 2011, 43, 1884-1890. [CrossRef] [PubMed]

26. Kim, J.H.; Shim, K.W.; Yoon, Y.S.; Lee, S.Y.; Kim, S.S.; Oh, S.W. Cigarette smoking increases abdominal and visceral obesity but not overall fatness: An observational study. PLoS ONE 2012, 7, e45815. [CrossRef] [PubMed]

27. Ho, L.C.; Yen, C.J.; Chao, C.T.; Chiang, C.K.; Huang, J.W.; Hung, K.Y. Visceral fat area is associated with $\mathrm{HbA1c}$ but not dialysate-related glucose load in nondiabetic PD patients. Sci. Rep. 2015, 5, 12811. [CrossRef] [PubMed]

(C) 2018 by the authors. Licensee MDPI, Basel, Switzerland. This article is an open access article distributed under the terms and conditions of the Creative Commons Attribution (CC BY) license (http:/ / creativecommons.org/licenses/by/4.0/). 